\title{
Article \\ Profilometer Comparison of the Surface Roughness of Four Denture Base Resins: An In Vitro Study
}

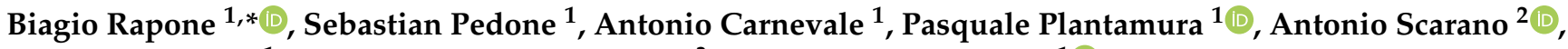 \\ Antonio Demelio ${ }^{1}$, Giuseppe Pompeo Demelio ${ }^{3}$ and Massimo Corsalini ${ }^{1}[\mathbb{C}$ \\ 1 Interdisciplinary Department of Medicine, University of Bari, 70121 Bari, Italy; \\ sebastianpedone12@gmail.com (S.P.); carnevaleantonello@gmail.com (A.C.); plantamura999@gmail.com (P.P.); \\ dr.antonio.demelio@gmail.com (A.D.); massimo.corsalini@uniba.it (M.C.) \\ 2 Department of Oral Science, Nano and Biotechnology and CeSi-Met University of Chieti-Pescara, \\ 66100 Chieti, Italy; ascarano@unich.it \\ 3 Department of Mechanics, Mathematics \& Management, Polytechnic of Bari, 70125 Bari, Italy; \\ giuseppepompeo.demelio@poliba.it \\ * Correspondence: biagiorapone79@gmail.com; Tel.: +39-3477619817
}

check for

updates

Citation: Rapone, B.; Pedone, S.;

Carnevale, A.; Plantamura, P.

Scarano, A.; Demelio, A.; Demelio,

G.P.; Corsalini, M. Profilometer

Comparison of the Surface

Roughness of Four Denture Base

Resins: An In Vitro Study. Appl. Sci.

2022, 12, 1837. https://doi.org/

10.3390/app12041837

Academic Editors: Paola Gandini and Andrea Scribante

Received: 8 December 2021

Accepted: 9 February 2022

Published: 10 February 2022

Publisher's Note: MDPI stays neutral with regard to jurisdictional claims in published maps and institutional affiliations.

Copyright: (C) 2022 by the authors. Licensee MDPI, Basel, Switzerland. This article is an open access article distributed under the terms and conditions of the Creative Commons Attribution (CC BY) license (https:// creativecommons.org/licenses/by/ $4.0 /)$.

\begin{abstract}
Background: The roughness of denture base materials is mainly affected by inherent material features, the polishing technique, and the operator's manual skills. The surface irregularities of the denture base resin's roughness profile is one of the components characterizing the superficial topography of dental prostheses, and it is a critical parameter for describing surface morphology. Generally, the increment of the surface roughness minimizes cleanability and promotes the rate of bacterial adherence, affecting the expression of bacterial adhesins. The purpose of this in vitro study was to investigate the roughness of four commercially available denture base resins employed for removable prosthodontics. Methods: Twenty-five specimens were realized and submitted to observation for three dimensions (vertically, horizontally, $45^{\circ}$ ). Average surface roughness (Ra), $\mathrm{Rv}$, $\mathrm{Rp}$, and Rq were measured with a calibrated mechanical roughness tester (Taylor Hobson Surtronic 25; Taylor Hobson, Leicester, UK). Data were analyzed through a Kruskal-Wallis test. Results: Significant differences in Ra between the groups were assessed. Baltic Denture System ${ }^{\mathrm{TM}}$ (Merz Dental GmbH; Lütjenburg, Germania) showed a lower surface roughness coefficient and a more homogeneous surface. Conclusions: The functional importance of surface roughness parameters for denture base materials must be explored, not only considering recognized surface features.
\end{abstract}

Keywords: surface roughness; resin; rugosimeter; bacterial adherence; prosthetic dentistry; dental materials

\section{Introduction}

The surface phenomena affect the morphology of dental prostheses, such as roughness [1]. Surface roughness is even an intrinsic property, and is one of the major clinical properties of the dental prosthesis which may be responsible for promotion of bacterial adhesion and biofilm organization [1-3]. In manufacturing processes, many factors, such as inaccuracy by the operator or in the device tools, or micro-scale irregularities, can alter the surface morphology [3]. The research in which roughness plays a prominent role has demonstrated that it is one of the factors that can physically inflict considerable damage to the oral environment, compromising the local ecological equilibrium. The adhesion of microorganisms is the crucial phase for the colonization of the material, followed by the production of extracellular polymer substances $[4,5]$. This process is characterized by physicochemical interactions, including the hydrophobicity and charge of the bacterial cell surface and the morphology of the resin material, as well as the potential of microorganisms to adhere to different surfaces [1]. Several studies have investigated the relationship between surface roughness and bacterial adhesion, reporting contradictory results [6-9]. 
The impact of physical properties of the materials in the bacterial adhesion has been largely discussed, describing the polymer surface irregularities of the material as the relevant property for the process in the adhesion of different microorganisms [3,7]. Literature data suggest the influence of a combination of mechanical and past polishing on the roughness surface $[4,8]$. The outcomes of the study conducted by Rutkunas et al. explained the effectiveness of polishing for generating smooth surfaces in both bis-acrylic and acrylic resins [10]. It has been proposed that the type of surface-polishing technique is critical for determining the surface roughness, as well as the type of acrylic resin employed. The measurement of the surface texture is an important aspect of prosthesis confection $[9,10]$. The most widely used and standardized method for the determination of surface roughness employs the profilometer, an instrument that contains a drive motor which traverses the pickup - a variable inductive-type [11] transducer-across the surface movements of the stylus relative to the skid, which are detected and converted into a proportional electrical signal, and which can be recorded for display or subsequent computer analysis. The Ra is the most-used international parameter of roughness, and it is normally determined as the arithmetic mean of the average absolute deviation of the roughness profile from the mean line over one sampling length [10,11]. Published studies, which evaluated the effects of the roughness surface in providing the retention of microorganisms, established that the Ra (the arithmetical average height) value that is clinically tolerable for a hard surface in the oral environment is $0.2 \mu \mathrm{m}$ on composite resin $(\mathrm{Ra}=0.179)$ [12]. The aim of this in vitro study was to compare the surface roughness level of four resins used to produce prosthetic bases, firstly by analyzing the Ra parameter, and then the statistical differences between the Rq, Rv, and Rp surface roughness parameters.

\section{Materials and Methods}

Twenty-five specimens of dental base resins were realized, and the mean of the arithmetic average of the absolute values of the profile height deviations from the mean line $(\mathrm{Ra})$, the root mean square average of the profile heights over the evaluation length $(\mathrm{Rq})$, the distance between the deepest valley of the profile and the mean line within the evaluation length $(\mathrm{Rv})$, and the distance between the highest point of the profile and the mean line within the evaluation length $(\mathrm{Rp})$ were calculated.

The surface roughness of all test specimens was determined using a profilometer. Roughness was measured in three dimensions for each sample: vertically, horizontally, and at $45^{\circ}$.

This in vitro study focused on the surface roughness of four different thermoplastic resin materials used for the fabrication of complete dentures: (1) microcrystalline polyamide denture base material (QUATTROTI SRL, DENTAL D-N). Polyamide is a thermoplastic material that is widely used as a denture base material because of its higher elasticity, toxicological safety, and because it is a chemical-resistant material; (2) the Baltic Denture System $^{\mathrm{TM}}$ (Merz Dental $\left.\mathrm{GmbH}\right)$, used for the fabrication of CAD/CAM complete dentures; (3) acrylic resin (ProBaseCold; IvoclarVivadent, Schaan, Liechtenstein); (4) acrylic resin (ProBaseHot; IvoclarVivadent, Schaan, Liechtenstein). Each resin material was processed according to the manufacturer's instruction: wax patterns were positioned into the slots of plasters $(10 \times 12 \times 3 \mathrm{~mm})$ (Figure 1$)$.

After the plaster was set, the wax patterns were carefully removed, and polymerization was accomplished at a pressure of 6 bars for 25 minutes for acrylic resin ProBaseCold and at pressure of 2 bars for 25 minutes for acrylic resin ProBaseHot. Twenty-five samples of each material were obtained for the analysis of Ra (Figure 2). 


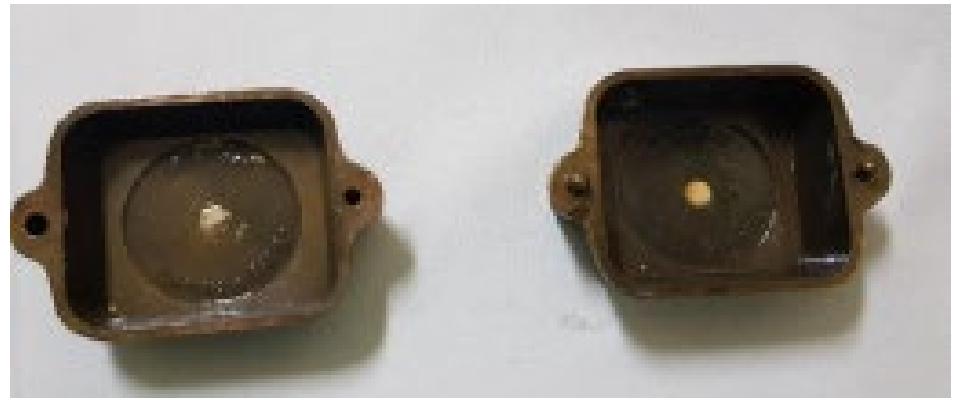

(a) The slots

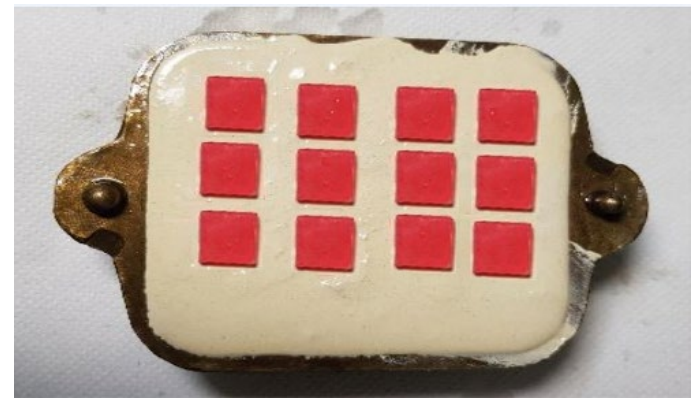

(b) The wax patterns into the slots

Figure 1. The slot of plasters $(\mathbf{a}, \mathbf{b})$.

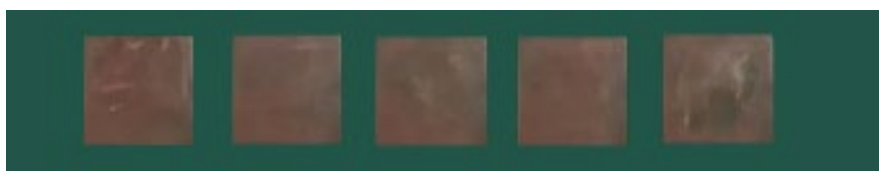

(a) Polyamide

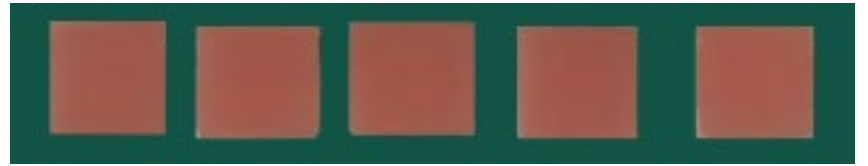

(b) Baltic

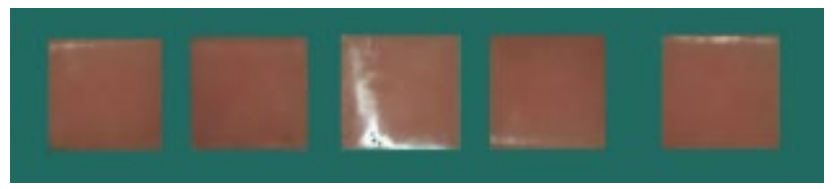

(c) ProBaseHot

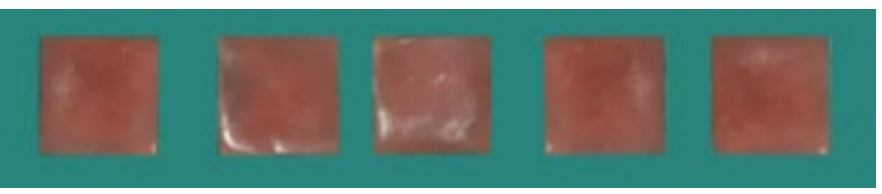

(d) ProBaseCold

Figure 2. Samples of each resin material (a-d).

\subsection{Surface Preparation}

Once the samples were cut to an appropriate size, they were ready for the grinding operation, finishing, and polishing. The purpose of grinding, which is by far the most important stage in preparation, was the mechanical removal of surface irregularities and the excess resin that covered the sample with rotary instruments. Then, the finishing and polishing were executed by using a tungsten-carbide bur (HM 79GX-040 HP; Meisinger, Centennial, CO, USA) with a thin cross, cut at $18,000 \mathrm{rpm}$ to remove any zone of main deformation consequent from the initial cutting. Then, a coarse-grain cylindrical rubber top bur for acrylic resin (Super Acrylic Polish; Lang Dental, Wheeling, IL, USA) was employed, and then a fine-grain cylindrical rubber top bur (Super Acrylic Polish) was used. Before polishing, samples were thoroughly cleaned and dried. The first polishing was accomplished using adhesive-backed emery paper, which is thought to be less aggressive: surfaces were planed using a hard napless without excessive weight pressing down on the samples. Intermediate cleaning was carried out to minimize the contamination of the abrasive materials. Cleaning was required to remove polishing residues. This requirement for cleanliness was also applied to the operator's hands. Final polishing was performed by using 6- or 3- $\mu \mathrm{m}$ diamond embedded on a napped cloth. Blocks with a 3-mm-thick layer 
were produced, providing 100 samples measuring $10 \times 12 \times 3 \mathrm{~mm}$. Then, the specimens were stored in distilled water at $37^{\circ} \mathrm{C}$ for $48 \pm 2 \mathrm{~h}$ prior testing.

The profilometric study of the degree of surface roughness was performed by using rugosimeter TAYLOR HOBSON Surtronic 25, following the method related to the reference surface.

\subsection{Statistical Analysis}

Data analysis was conducted employing IBM SPSS 20.0 Statistics for Mac (IBM Inc., New York, NY, USA). Summary statistics were calculated for Ra, Rv, Rp, and Rq. A KruskalWallis rank sum test was conducted to assess if there were significant differences in $\mathrm{Ra}, \mathrm{Rv}$, $\mathrm{Rp}$, and Rq between the levels of the group.

\section{Results}

\subsection{Summary Statistics}

The summary statistics can be found in Table 1 .

Table 1. Statistics summary table for interval and ratio variables.

\begin{tabular}{|c|c|c|c|c|c|c|c|c|}
\hline Group & Variable & Min & Max & Range & Median & $s^{2}$ & IQR & SS \\
\hline \multicolumn{9}{|c|}{$\mathrm{Ra}$} \\
\hline Мyс & & 6.7 & 9.32 & 2.62 & 8 & 1.25 & 2.22 & 7.52 \\
\hline Baltic & & 4.6 & 7.6 & 3 & 6 & 1.25 & 2.2 & 7.53 \\
\hline ProBase Hot & & 5.67 & 8.12 & 2.45 & 6.89 & 0.91 & 2.09 & 5.49 \\
\hline ProBase Cold & & 5.98 & 8.76 & 2.78 & 7.76 & 0.94 & 1.56 & 5.69 \\
\hline \multicolumn{9}{|c|}{$\mathrm{Rv}$} \\
\hline Мyc & & 8.12 & 9.6 & 1.48 & 9.12 & 0.27 & 0.87 & 1.64 \\
\hline Baltic & & 7.89 & 9.13 & 1.24 & 8.34 & 0.20 & 0.81 & 1.22 \\
\hline ProBase Hot & & 11.23 & 15.55 & 4.32 & 14.78 & 2.57 & 2.67 & 15.44 \\
\hline ProBase Cold & & 8.12 & 9.78 & 1.66 & 9.12 & 0.366 & 1.1 & 2.2 \\
\hline \multicolumn{9}{|c|}{$\mathrm{Rp}$} \\
\hline Мус & & 10.89 & 13.11 & 2.22 & 12.89 & 0.67 & 0.98 & 4.05 \\
\hline Baltic & & 5.67 & 12.12 & 6.45 & 9.89 & 4.68 & 3.34 & 28.08 \\
\hline ProBase Hot & & 10.56 & 12.34 & 1.78 & 11.76 & 0.47 & 1.34 & 2.83 \\
\hline ProBase Cold & & 8.66 & 11.56 & 2.9 & 10.12 & 0.78 & 0.91 & 4.73 \\
\hline \multicolumn{9}{|c|}{$\mathrm{Rq}$} \\
\hline Мyc & & 37.67 & 43.12 & 5.45 & 40.12 & 22.66 & 1.26 & 16.01 \\
\hline Baltic & & 21.56 & 34.56 & 5 & 32.12 & 13.35 & 2.99 & 20.1 \\
\hline ProBase Hot & & 26.67 & 36.89 & 10.22 & 31.56 & 12.62 & 5.89 & 75.73 \\
\hline ProBase Cold & & 29.56 & 39.12 & 17.12 & 34.56 & 35.21 & 7.67 & 65.14 \\
\hline
\end{tabular}

Sample Minimum (Min): The smallest numeric value in a given sample; Sample Maximum (Max): The largest numeric value in a given sample.

\subsection{Kruskal-Wallis Rank Sum Test}

Ra: The results of the Kruskal-Wallis test were significant based on an alpha value of $0.05, \chi^{2}(3)=8.23, p=0.041$, indicating that the mean rank of Ra was significantly different between the levels of Group. Table 2 presents the results of the Kruskal-Wallis rank sum test. Figure 3 presents boxplots of the ranked values of Ra by the levels of Group. 
Table 2. Kruskal-Wallis rank sum test for Ra by group.

\begin{tabular}{lrrrr}
\hline Level & Mean Rank & $\chi^{2}$ & $d f$ & $p$ \\
\hline Myc & 19.86 & 8.23 & 3 & 0.041 \\
Baltic & 8.21 & & \\
ProBase Hot & 12.64 & & \\
ProBase Cold & 17.29 & & \\
\hline
\end{tabular}

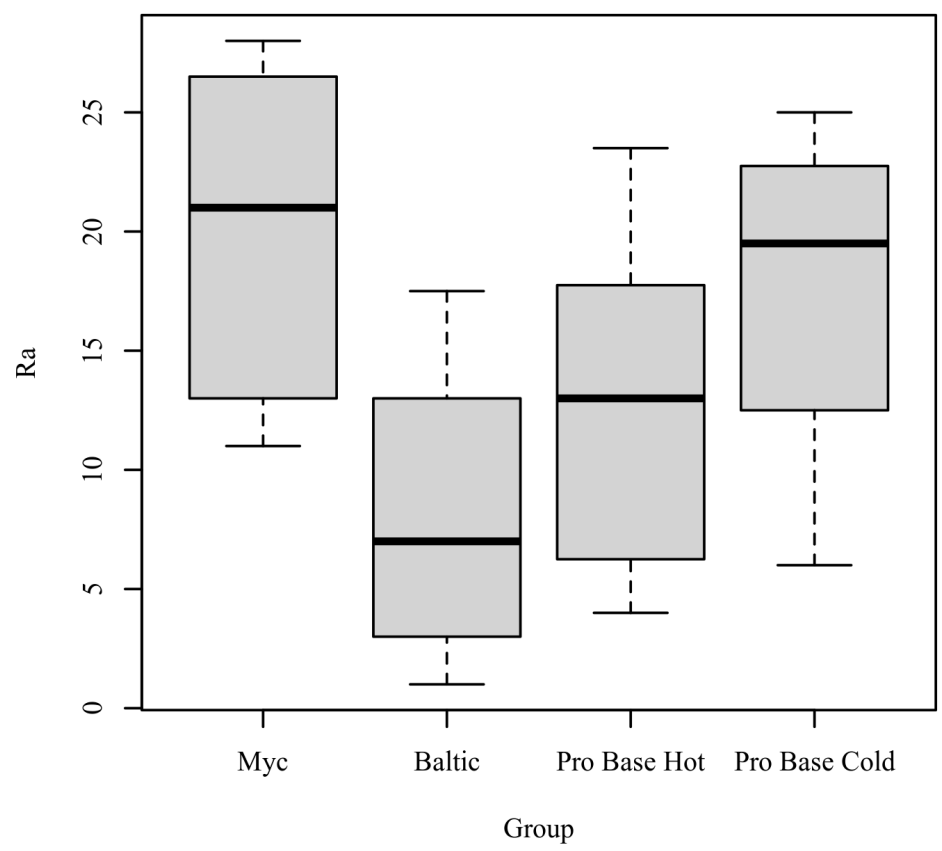

Figure 3. Ranked Values of Ra by level of Group.

Post hoc. Pairwise comparisons were examined between each level of Group. The results of the multiple comparisons indicated significant differences based on an alpha value of 0.05 between Myc-Baltic. Table 3 presents the results of the pairwise comparisons.

Table 3. Pairwise comparisons for the mean ranks of Ra by level of group.

\begin{tabular}{lrr}
\hline Comparison & Observed Difference & Critical Difference \\
\hline Myc-Baltic & 11.64 & 11.60 \\
Myc-ProBase Hot & 7.21 & 11.60 \\
Myc-ProBase Cold & 2.57 & 11.60 \\
Baltic-ProBase Hot & 4.43 & 11.60 \\
Baltic-ProBase Cold & 9.07 & 11.60 \\
ProBase Hot-ProBase Cold & 4.64 & 11.60 \\
\hline
\end{tabular}

Note. Observed Differences $>$ Critical Differences indicate significance at the $p<0.0500$ level.

Rv: The results of the Kruskal-Wallis test were significant based on an alpha value of $0.05, \chi^{2}(3)=17.47, p<0.001$, indicating that the mean rank of $\mathrm{Rv}$ was significantly different between the levels of Group. Table 4 presents the results of the Kruskal-Wallis rank sum test. Figure 4 presents boxplots of the ranked values of Rv by the levels of Group. 
Table 4. Kruskal-Wallis rank sum test for Rv by group.

\begin{tabular}{lrrrr}
\hline Level & Mean Rank & $\chi^{2}$ & $d f$ & $p$ \\
\hline Myc & 13.50 & 17.47 & 3 & $<0.001$ \\
Baltic & 7.29 & & & \\
ProBase Hot & 25.00 & & & \\
ProBase Cold & 12.21 & & & \\
\hline
\end{tabular}

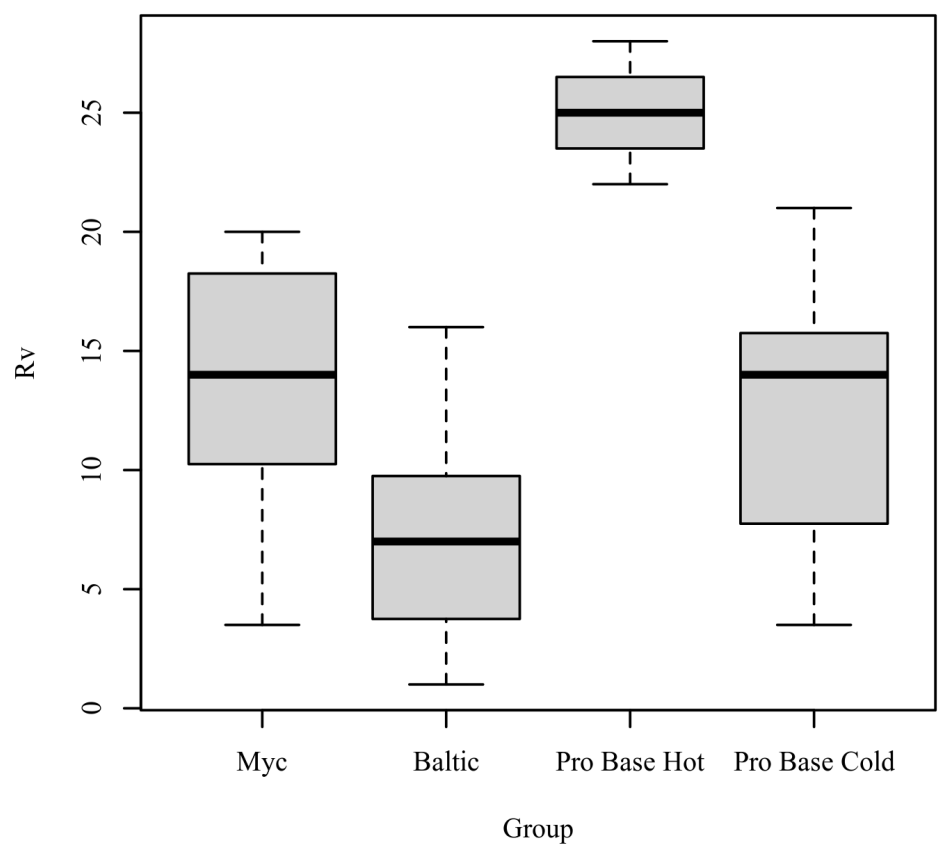

Figure 4. Ranked values of Rv by level of Group.

Post hoc. Pairwise comparisons were examined between each level of Group. The results of the multiple comparisons indicated significant differences based on an alpha value of 0.05 between the following variable pairs: Baltic-ProBase Hot and ProBase Hot-ProBase Cold. Table 5 presents the results of the pairwise comparisons.

Table 5. Pairwise comparisons for the mean ranks of Rv by level of group.

\begin{tabular}{lrr}
\hline Comparison & Observed Difference & Critical Difference \\
\hline Myc-Baltic & 6.21 & 11.60 \\
Myc-ProBase Hot & 11.50 & 11.60 \\
Myc-ProBase Cold & 1.29 & 11.60 \\
Baltic-ProBase Hot & 17.71 & 11.60 \\
Baltic-ProBase Cold & 4.93 & 11.60 \\
ProBase Hot-ProBase Cold & 12.79 & 11.60 \\
\hline
\end{tabular}

Note. Observed Differences $>$ Critical Differences indicate significance at the $p<0.0500$ level.

Rp: The results of the Kruskal-Wallis test were significant based on an alpha value of $0.05, \chi^{2}(3)=16.19, p=0.001$, indicating that the mean rank of Rp was significantly different between the levels of Group. Table 6 presents the results of the Kruskal-Wallis rank sum test. Figure 5 presents boxplots of the ranked values of Rp by the levels of Group. 
Table 6. Kruskal-Wallis rank sum test for Rp by group.

\begin{tabular}{lrrrr}
\hline Level & Mean Rank & $\chi^{2}$ & $d f$ & $p$ \\
\hline Myc & 23.43 & 16.19 & 3 & 0.001 \\
Baltic & 8.43 & & \\
ProBase Hot & 17.29 & & \\
ProBase Cold & 8.86 & & \\
\hline
\end{tabular}

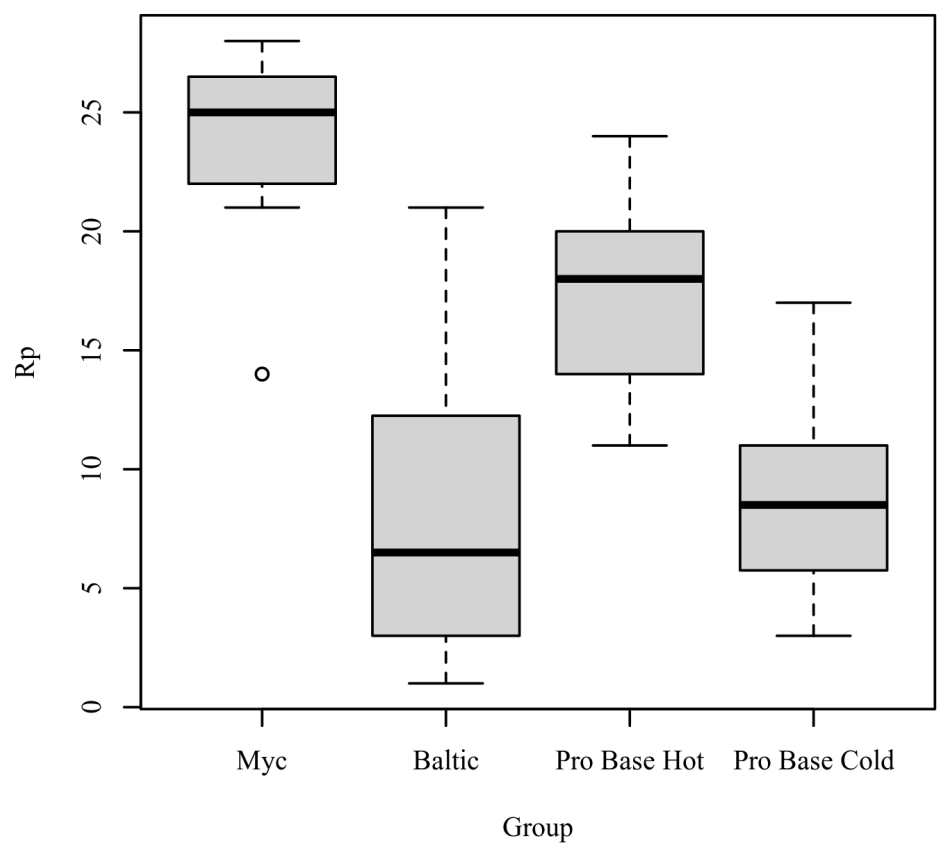

Figure 5. Ranked values of Rp by levels of group.

Post hoc. Pairwise comparisons were examined between each level of Group. The results of the multiple comparisons indicated significant differences based on an alpha value of 0.05 between the following variable pairs: Myc-Baltic and Myc-ProBase Cold. Table 7 presents the results of the pairwise comparisons.

Table 7. Pairwise comparisons for the mean ranks of Rp by level of group.

\begin{tabular}{lrr}
\hline Comparison & Observed Difference & Critical Difference \\
\hline Myc-Baltic & 15.00 & 11.60 \\
Myc-ProBase Hot & 6.14 & 11.60 \\
Myc-ProBase Cold & 14.57 & 11.60 \\
Baltic-ProBase Hot & 8.86 & 11.60 \\
Baltic-ProBase Cold & 0.43 & 11.60 \\
ProBase Hot-ProBase Cold & 8.43 & 11.60 \\
\hline Note. Observed Differences > Critical Differences indicate significance at the $p<0.0500$ level.
\end{tabular}

Rq: The results of the Kruskal-Wallis test were significant based on an alpha value of $0.05, \chi^{2}(3)=15.64, p=0.001$, indicating that the mean rank of Rq was significantly different between the levels of Group. Table 8 presents the results of the Kruskal-Wallis rank sum test. Figure 6 presents boxplots of the ranked values of Rq by the levels of Group. 
Table 8. Kruskal-Wallis rank sum test for Rq by group.

\begin{tabular}{lrrrr}
\hline Level & Mean Rank & $\chi^{2}$ & $d f$ & $p$ \\
\hline Myc & 24.86 & 15.64 & 3 & 0.001 \\
Baltic & 9.71 & & & \\
ProBase Hot & 10.07 & & & \\
ProBase Cold & 13.36 & & & \\
\hline
\end{tabular}

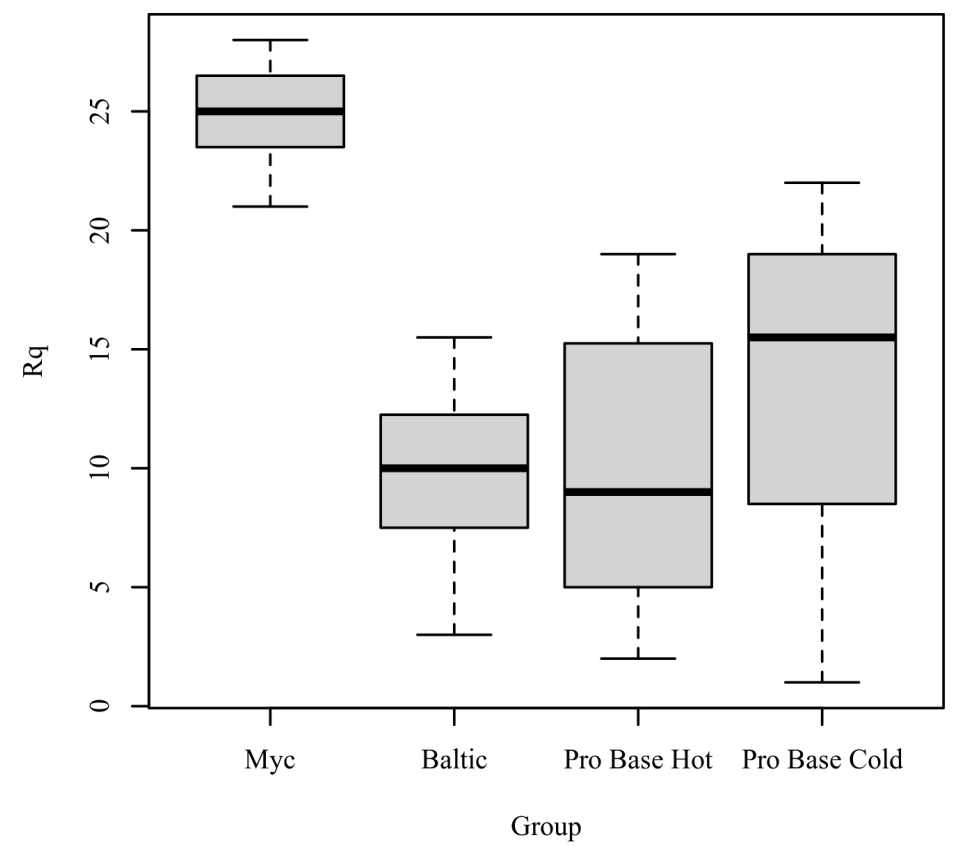

Figure 6. Ranked values of Rq by level of group.

Post hoc. Pairwise comparisons were examined between each level of group. The results of the multiple comparisons indicated significant differences based on an alpha value of 0.05 between the following variable pairs: Myc-Baltic and Myc-ProBase Hot. Table 9 presents the results of the pairwise comparisons.

Table 9. Pairwise comparisons for the mean ranks of Rq by level of group.

\begin{tabular}{lrr}
\hline Comparison & Observed Difference & Critical Difference \\
\hline Myc-Baltic & 15.14 & 11.60 \\
Myc-ProBase Hot & 14.79 & 11.60 \\
Myc-ProBase Cold & 11.50 & 11.60 \\
Baltic-ProBase Hot & 0.36 & 11.60 \\
Baltic-ProBase Cold & 3.64 & 11.60 \\
ProBase Hot-ProBase Cold & 3.29 & 11.60 \\
\hline
\end{tabular}

Note. Observed Differences $>$ Critical Differences indicate significance at the $p<0.0500$ level.

\section{Discussion}

The purpose of this in vitro study was to perform an analysis of surface roughness. By definition, roughness refers to the parameter that measures the spaced micro-irregularities on the surface texture [13-16]. The surface roughness is a critical property of resin material, which directly increases the risk of oral bacterial colonization [13-17]. Concerning the relationship between the surface property of roughness of dental prostheses and the increase of bacterial adhesion and biofilm formation, the manufacturing phases and different resin materials have been largely investigated [13,14,17-22]. Specifically, several studies have focused on the resin material, suggesting that the composition of the resin matrix, the size 
and distribution of the particles of the resins, and the chemical nature of the material may affect the polishing stage [6,13-25]. In general, polymethyl methacrylate (PMMA) resin, a synthetic resin produced from the polymerization of methyl methacrylate, performed better in roughness surface testing than the other materials [26]. Polishing is a critical step of prosthetic bases' production, and its efficiency is strictly correlated to the surface smoothness $[1,4,18,19]$. Several studies assessed the impact of chemical and mechanical polishing on the roughness of acrylic resins used in prosthetic bases, achieving the lowest roughness values with the mechanical polishing. Young et al. [9] and Gantz et al. [27] compared the surface roughness values of the bis-acrylic resins with the acrylic resins, showing the lower roughness values of the bis-acryl resins [28]. These results were in contrast with the observations reported by Sen et al. [29], Haselton et al. [11], and Rutkunas et al. [10], which supported the hypothesis of the heterogeneous design of the bis-acryl resins. The differences were found to be statistically significant. This difference in roughness property between the materials could be attributed to the manufacturing process [11,15]. In our study, the higher surface roughness values were observed for the Baltic resin, a currently available CAD/CAM material. Baltic resin is widely used in CAD/CAM manufacturing techniques. This technology is an improvement over manual processes and minimizes the negative impact of manual manipulation. However, our findings are in contrast with previous results, which reported less roughness surface values for $\mathrm{CAD} / \mathrm{CAM}$ resin, suggesting that the resin may possess differences in composition or manufacturing process $[3,7,9]$. In accordance with previous studies, these results have shown that the manipulation technique (powder-liquid) is operator-dependent and may result from comparing the homogeneous composition [2-5,10,14,30-32].

\section{Conclusions}

The limitation of this study is due to the intrinsic nature of in vitro studies, which do not recreate the natural conditions. Indeed, in clinical practice, the increasing of the roughness of a prosthesis is supported by the occlusal adjustments during the prosthesis confection. It was observed that there was a significant statistical difference comparing the Ra roughness values obtained by the different resins. The f-ratio value is 16.46 . The $p$-value is $<0.00001$. Within the limitations of this in vitro study, the reliable conclusion is that the smoothness is the goal of achieving an ideal dental prosthesis surface, but further testing of the properties of materials are needed to determine the exhaustive analysis of roughness parameter, especially by in vivo observation.

Author Contributions: Conceptualization, B.R.; methodology, B.R.; software, B.R.; validation, B.R. and M.C.; formal analysis, B.R., M.C., and G.P.D.; investigation, B.R. and M.C.; resources, B.R.; data curation, B.R., G.P.D., and. M.C.; writing-original draft preparation, B.R.; writing-review and editing, B.R. and M.C.; visualization, B.R., S.P., A.C., P.P., A.S., and A.D.; supervision, B.R. and M.C.; project administration B.R. and M.C. All authors have read and agreed to the published version of the manuscript.

Funding: This research received no external funding.

Institutional Review Board Statement: Not applicable for studies not involving humans or animals.

Informed Consent Statement: Informed consent was obtained from all subjects involved in the study.

Conflicts of Interest: The authors declare no conflict of interest.

\section{References}

1. Mayahara, M.; Kataoka, R.; Arimoto, T.; Tamaki, Y.; Yamaguchi, N.; Watanabe, Y.; Yamasaki, Y.; Miyazaki, T. Effects of surface roughness and dimorphism on the adhesion of Candida albicans to the surface of resins: Scanning electron microscope analyses of mode and number of adhesions. J. Investig. Clin. Dent. 2014, 5, 307-312. [CrossRef] [PubMed]

2. Quaglia, E.; Moscufo, L.; Corsalini, M.; Coscia, D.; Sportelli, P.; Cantatore, F.; De Rinaldis, C.; Rapone, B.; Carossa, M.; Carossa, S. Polyamide vs silk sutures in the healing of postextraction sockets: A split mouth study. Oral Implantol. 2018, 11, 115-120. 
3. Zissis, A.J.; Polyzois, G.L.; Yannikakis, S.A.; Harrison, A. Roughness of denture materials: A comparative study. Int. J. Prosthodont. 2000, 13, 136-140.

4. Taylor, R.L.; Bulad, K.; Verran, J.; McCord, J.F. Colonization and deterioration of soft denture lining materials in vivo. Eur. J. Prosthodont. Restor. Dent. 2008, 16, 50-55. [CrossRef] [PubMed]

5. Corsalini, M.; Di Venere, D.; Carossa, M.; Ripa, M.; Sportelli, P.; Cantatore, F.; De Rinaldis, C.; Di Santantonio, G.; Lenoci, G.; Barile, G.; et al. Comparative clinical study between zirconium-ceramic and metal-ceramic fixed rehabilitations. Oral Implantol. 2018, 11, 150-160.

6. Mutluay, M.M.; Oğuz, S.; Ørstavik, D.; Fløystrand, F.; Doğan, A.; Söderling, E.; Närhi, T.; Olsen, I. Experiments on in vivo biofilm formation and in vitro adhesion of Candida species on polysiloxane liners. Gerodontology 2010, 27, 283-291. [CrossRef]

7. Corsalini, M.; Di Venere, D.; Sportelli, P.; Magazzino, D.; Ripa, M.; Cantatore, F.; Cagnetta, C.; De Rinaldis, C.; Montemurro, N.; De Giacomo, A.; et al. Evaluation of prosthetic quality and masticatory efficiency in patients with total removable prosthesis: Study of 12 cases. Oral Implantol. 2018, 11, 230-240.

8. Sarıkaya, I.; Yerliyurt, K.; Hayran, Y. Effect of surface finishing on the colour stability and translucency of dental ceramics. BMC Oral Health 2018, 18, 40. [CrossRef] [PubMed]

9. Young, H.M.; Smith, C.T.; Morton, D. Comparative in vitro evaluation of two provisional restorative materials. J. Prosthet. Dent. 2001, 85, 129-132. [CrossRef]

10. Rutkunas, V.; Sabaliauskas, V. Effects of different repolishing techniques on colour change of provisional prosthetic materials. Stomatologija 2009, 11, 102-112.

11. Haselton, D.R.; Diaz Arnold, A.M.; Dawson, D.V. Color stability of provisional crown and fixed partial denture resins. J. Prosthet. Dent. 2005, 93, 70-75. [CrossRef]

12. Grassi, F.R.; Grassi, R.; Rapone, B.; Gianfranco, A.; Balena, A.; Kalemaj, Z. Dimensional changes of buccal bone plate in immediate implants inserted through open flap, open flap and bone grafting, and flapless technique. A CBCT randomized controlled clinical trial. Clin. Oral Implants Res. 2019, 30, 1155-1164. [CrossRef] [PubMed]

13. Arciola, C.R.; Campoccia, D.; Speziale, P.; Montanaro, L.; Costerton, J.W. Biofilm formation in Staphylococcus implant infections A review of molecular mechanisms and implications for biofilm-resistant materials. Biomaterials 2012, 33, 5967-5982. [CrossRef] [PubMed]

14. Veyries, M.L.; Faurisson, F.; Joly-Guillou, M.L.; Rouveix, B. Control of staphylococcal adhesion to polymethylmethacrylate and enhancement of susceptibility to antibiotics by poloxamer 407. Antimicrob. Agents Chemother. 2000, 44, 1093-1096. [CrossRef]

15. Rapone, B.; Palmisano, C.; Ferrara, E.; Di Venere, D.; Albanese, G.; Corsalini, M. The Accuracy of Three Intraoral Scanners in the Oral Environment with and without Saliva: A Comparative Study. Appl. Sci. 2020, 10, 7762. [CrossRef]

16. Vacheethasanee, K.; Marchant, R.E. Surfactant polymers designed to suppress bacterial (Staphylococcus epidermidis) adhesion on biomaterials. J. Biomed. Mater. Res. 2000, 50, 302-312. [CrossRef]

17. Singh, D.; Kaur, H.; Gardner, W.G.; Treen, L.B. Bacterial contamination of hospital pagers. Infect. Control Hosp. Epidemiol. 2002, 23, 274-276. [CrossRef]

18. Scarano, A.; Inchingolo, F.; Rapone, B.; Festa, F.; Tari, S.R.; Lorusso, F. Protective Face Masks: Effect on the Oxygenation and Heart Rate Status of Oral Surgeons during Surgery. Int. J. Environ. Res. Public Health 2021, 18, 2363. [CrossRef]

19. Guler, A.U.; Kurt, S.; Kulunk, T. Effects of various finishing procedures on the staining of provisional restorative materials. J. Prosthet. Dent. 2005, 93, 453-458. [CrossRef]

20. Rishi, E.; Rishi, P.; Nandi, K.; Shroff, D.; Therese, K.L. Endophthalmitis caused by Enterococcus faecalis: A case series. Retina 2009, 29, 214-217. [CrossRef] [PubMed]

21. Peng, C.H.; Cheng, C.K.; Chang, C.K.; Chen, Y.L. Multiresistant enterococci: A rare cause of complicated corneal ulcer and review of the literature. Can. J. Ophthalmol. 2009, 44, 214-215. [CrossRef]

22. Paranhos, R.M.; Batalhão, C.H.; Semprini, M.; Regalo, S.C.; Ito, I.Y.; Chiarello de Mattos, M.d.G. Evaluation of ocular prosthesis biofilm and anophthalmic cavity contamination after use of three cleansing solutions. J. Appl. Oral Sci. 2007, 15, 33-38. [CrossRef] [PubMed]

23. Rapone, B.; Ferrara, E.; Corsalini, M.; Converti, I.; Grassi, F.R.; Santacroce, L.; Topi, S.; Gnoni, A.; Scacco, S.; Scarano, A.; et al. The Effect of Gaseous Ozone Therapy in Conjunction with Periodontal Treatment on Glycated Hemoglobin Level in Subjects with Type 2 Diabetes Mellitus: An Unmasked Randomized Controlled Trial. Int. J. Environ. Res. Public Health 2020, $17,54675$. [CrossRef]

24. Williams, M.A.; McMullan, R.; Hedderwick, S.; Mulholland, D.A.; Best, R.M. Diagnosis and treatment of endogenous fungal endophthalmitis. Ophthalmologica. 2006, 220, 134-136. [CrossRef]

25. Katsikogianni, M.; Missirlis, Y.F. Concise review of mechanisms of bacterial adhesion to biomaterials and of techniques used in estimating bacteria-material interactions. Eur. Cell Mater. 2004, 8, 37-57. [CrossRef] [PubMed]

26. Yoda, I.; Koseki, H.; Tomita, M.; Shida, T.; Horiuchi, H.; Sakoda, H.; Osaki, M. Effect of surface roughness of biomaterials on Staphylococcus epidermidis adhesion. BMC Microbiol. 2014, 14, 234. [CrossRef]

27. Gantz, L.; Fauxpoint, G.; Arntz, Y.; Pelletier, H.; Etienne, O. In vitro comparison of the surface roughness of polymethyl methacrylate and bis-acrylic resins for interim restorations before and after polishing. J. Prosthet. Dent. 2021, 125, 833.e1-833.e10. [CrossRef] 
28. Rapone, B.; Corsalini, M.; Converti, I.; Loverro, M.T.; Gnoni, A.; Trerotoli, P.; Ferrara, E. Does Periodontal Inflammation Affect Type 1 Diabetes in Childhood and Adolescence? A Meta-Analysis. Front. Endocrinol. 2020, 11, 278. [CrossRef] [PubMed]

29. Sen, D.; Göller, G.; Isssever, H. The effect of two polishing pastes on the surface roughness of bis-acryl composite and methacrylate based resins. J. Prosthet. Dent. 2002, 88, 527-532. [CrossRef]

30. Quirynen, M.; Bollen, C.M. The influence of surface roughness and surface-free energy on supra- and subgingival plaque formation in man. A review of the literature. J. Clin. Periodontol. 1995, 22, 1-4. [CrossRef]

31. Rashid, H. The effect of surface roughness on ceramics used in dentistry: A review of literature. Eur. J. Dent. 2014, 8, 571-579. [CrossRef] [PubMed]

32. Silva, S.; Pires, P.; Monteiro, D.R.; Negri, M.; Gorup, L.F.; Camargo, E.R.; Barbosa, D.B.; Oliveira, R.; Williams, D.W.; Henriques, M.; et al. The effect of silver nanoparticles and nystatin on mixed biofilms of Candida glabrata and Candida albicans on acrylic. Med. Mycol. 2013, 51, 178-184. [CrossRef] [PubMed] 